\section{Pancuronium added to intravenous regi onal anesthesia: systemic weakness after prolonged tourniquet inflation time}

To the Editor:

$\mathrm{N}$ euromuscular blockers (NMBs) may be added to intravenous regional anesthesia (IVRA) to enhance both the motor and sensory blockade.1,2M ost reports indicated lack of systemic effects with these agents but we encountered a case of weakness upon tourniquet deflation with the use of pancuronium despite a tourniquet inflation time of $89 \mathrm{~min}$.

A healthy $41-y \mathrm{r}-0 \mathrm{dd}, 81 \mathrm{~kg}$ man presented for repair of a lacerated right extensor pollicis longus tendon and IVRA was performed with 40 lidocaine $\mathrm{ml} 0.7 \%$ plus $2 \mathrm{mg}$ pancuronium. This quantity of pancuronium was inadvertently administered instead of the 1 mg dose typically used at our institution. The block was performed in the standard manner, with exsanguination of the arm and inflation of a double-cuffed tourniquet to $300 \mathrm{mmH} \mathrm{g}$. The tourniquet was deflated after $89 \mathrm{~min}$. Three minutes later the patient experienced diplopia and was unable to lift his head. Intravenous administration of $2.5 \mathrm{mg}$ neostigmine (with $0.5 \mathrm{mg}$ glycopyrrolate) terminated the diplopia and allowed a sustained head lift for $>5 \mathrm{sec}$.

The apparent systemic release of a substantial quantity of N M B in this case is in contrast to that of local anesthetics, in which one would expect no systemic effects after deflation of a tourniquet which had been inflated for $89 \mathrm{~min}$. The differences probably relate to the lesser extremity tissue binding with N M Bs due to their greater ionization and lower lipid solubility. Clinicians who add NMBs to IVRA should be aware of the potential for systemic weakness, even after prolonged tourniquet inflation.

M ona G. Sarkiss M D PhD

$M$. D enise $D$ aley M D M SC FRCPC DABA

Peter $\mathrm{H}$. N orman M D FRCPC DABA

Lewis A. Coveler MD FACA DABA

H ouston, Texas, USA

\section{References}

$1 \mathrm{M} \mathrm{cGlone} R$, $\mathrm{H}$ eyes $\mathrm{F}, \mathrm{H}$ arris $\mathrm{P}$. The use of a muscle relaxant to supplement local anaesthetics for Bier's blocks. Arch Emerg M ed 1988; 5: 79-85.

2 Elhakim M, Sadek RA. Addition of atracurium to lidocaine for intravenous regional anaesthesia. Acta Anaesthesiol Scand 1994; 38: 542-4.

\section{Subcutaneoustunnelling of intersca- lene catheters}

To the Editor:

I read with interest the interscalene catheter tunnelling technique suggested by D rs. Ekatodromis and Borgeat. ${ }^{1}$ I also use an intravenous cannula for catheter tunnelling but my technique keeps the catheter completely subcutaneous until it emerges above the clavicle, unlike the above technique, which appears to involve the emergence of the catheter onto the skin for a few millimetres before it is tunnelled. As Winnie commented: "With the interscalene technique, the catheter is at right angles to the... skin, so that movement of the head or shoulders tends to advance or withdraw the catheter". ${ }^{2}$ I use the follow ing technique.

Before inserting the interscalene catheter, a 2-3 $\mathrm{mm}$ skin incision is made. The catheter is then inserted through this incision. An 18G intravenous cannula needle is inserted alongside the catheter and is advanced subcutaneously to a point just above the clavicle. It is then pushed outwards through the skin (Figure 1a). The intravenous cannula is passed backwards over the needle and the two are withdrawn together, allowing the end of the cannula to emerge through the skin incision (Figure $1 \mathrm{~b}$ ). The catheter is then passed through the cannula (Figure $1 \mathrm{C}$ ), which is removed. The result is a fully tunnelled catheter. The skin incision is closed with a Steristrip ${ }^{\mathrm{TM}}$.

On a slightly peevish note: if $\mathrm{Dr}$. Borgeat wishes to quote an earlier publication than his $^{3}$ that introduces the concept of patient-controlled interscalene analgesia,

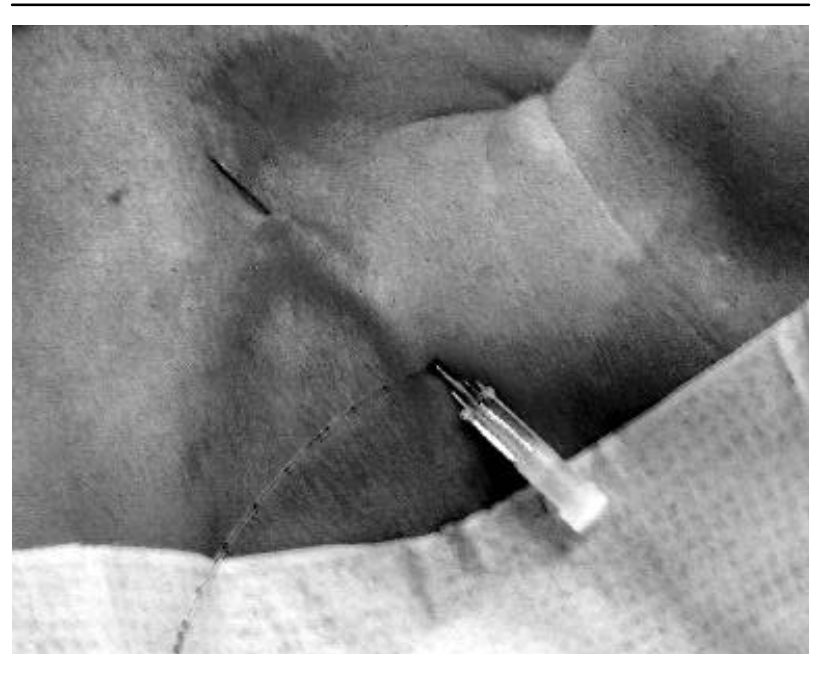

FIGURE 1A 